\title{
CENÁRIO DAS EMBALAGENS PÓS-CONSUMO DE SANEANTES DESINFESTANTES DE USO PROFISSIONAL EM ALAGOINHAS-BA: UMA ANÁLISE CRÍTICA
}

\section{SCENARIO OF POST-CONSUMER PACKAGING OF URBAN PESTICIDES FOR PROFESSIONAL USE IN ALAGOINHAS-BA: A CRITICAL ANALYSIS}

Grice Anne dos Santos Vaz

Mestrado em Meio Ambiente, Águas e Saneamento/Escola Politécnica da UFBA. Universidade Federal da Bahia. (griceannevaz@hotmail.com)

Luiz Roberto Santos Moraes

PhD em Saúde Ambiental/University of London-UK. Departamento de Engenharia Ambiental da Escola Politécnica da Universidade Federal da Bahia. (moraes@ufba.br)

Submissão: 03 de Março de 2019 Aceite: 03 de Setembro de 2019

\section{Resumo}

A realização do controle químico de pragas e vetores urbanos executado por empresas especializadas e nas campanhas de saúde pública gera como resíduo sólido as embalagens pós-consumo dos saneantes desinfestantes que, em diversos aspectos, dentre eles, a sua composição e toxicidade, são comparados aos dos agrotóxicos. Esses resíduos ainda são pouco discutidos, sendo escassos os trabalhos que se preocupam com o tema, e o cenário é pouco evidente. Diante desse contexto, este artigo tem como objetivo analisar os sistemas de gerenciamento das embalagens vazias de saneantes desinfestantes de uso profissional no município de Alagoinhas-BA. Após pesquisa bibliográfica e documental, a coleta de dados foi realizada por meio de entrevista semiestruturada com o Poder Público e as empresas especializadas no controle de pragas e vetores urbanos, bem como de observação em campo nas empresas e órgãos públicos investigados. A análise das entrevistas e das informações documentais ocorreu com o uso da técnica análise de conteúdo. Todas as informações e registro das observações em campo foram comparados com o estabelecido na legislação e normas da Agência Nacional de Vigilância Sanitária (ANVISA). Dos recipientes gerados, 30,68\% são representados por laváveis (recicláveis), e 69,32\% por não laváveis (não recicláveis). A logística reversa ainda não foi implementada por todos os geradores desse resíduo, e entre alguns obstáculos podem ser citados o custo operacional no transporte, a ausência da realização de etapas intra-estabelecimento, e o não envolvimento de todos os agentes implicados no ciclo de vida do produto. Embora exista um Programa para o recebimento de algumas embalagens que circulam nesse setor de controle de pragas, ainda é pouco difundido e não contempla o município de Alagoinhas. A falta de controle no setor favorece a atuação ilegal, a qual se torna fonte de canais clandestinos da geração desses resíduos perigosos.

Palavras-chave: Resíduos sólidos; Saneantes desinfestantes de uso profissional; Política Nacional de Resíduos Sólidos; Logística reversa; Responsabilidade compartilhada.

\section{Abstract}

The chemical control of pests and urban vectors carried out by specialized companies and in the public health campaigns generates as solid waste the post-consumer packages of urban pesticide for professional use, which in several aspects, due to their composition and toxicity, are compared to the agricultural pesticides. These residues are still little discussed, there are few works that are concerned with the theme, and the scenario is not very evident. In view of this context, the objective of this work was to analyze the management systems of empty urban pesticide for professional use containers in the municipality of Alagoinhas-Bahia-Brazil. Data collection was carried out through bibliographic research, semi-structured interviews with the Public Authorities and companies specialized in pest control and urban vectors, documentary analysis and field observation in companies and public agencies investigated. The analysis of interviews and documentary information was carried out using the technique of content analysis. All 
information and records of the field observations were compared to the established legislation and standards of the Brazilian Agency of Sanitary Surveillance (ANVISA). Of the containers generated, $30.68 \%$ are represented by washable (recyclable), and $69.32 \%$ by non-washable (non-recyclable). The reverse logistics has not yet been implemented by all the generators of this waste, and among some obstacles can be mentioned the operational cost in transportation, the absence of intra-establishment stages, and the noninvolvement of all agents involved in the life cycle of product. Although there is a Program to receive some packaging that circulates in this sector of pest control, it is still not widespread and does not contemplate Alagoinhas. The lack of control in the sector favors illegal activity that becomes the source of clandestine channels for the generation of such hazardous waste.

Keywords: Solid waste; Urban pesticide for professional use; Brazilian Policy on Solid Wastes; Logistic reverse; Shared responsibility.

\section{INTRODUÇÃO}

Os saneantes desinfestantes são os produtos registrados na Agência Nacional de Vigilância Sanitária (ANVISA) destinados à desinfestação de ambientes urbanos, sejam eles residenciais, coletivos, públicos ou privados, os quais matam, inativam ou repelem organismos indesejáveis no ambiente, objetos, superfícies inanimadas ou em plantas. Incluem-se neste conceito os termos "inseticidas", "reguladores de crescimento", "rodenticidas", "moluscicidas" e "repelentes" (BRASIL, 2009). Os saneantes classificados como de "uso profissional" ou "venda restrita a instituições especializadas" são os que não podem ser vendidos diretamente ao público e devem ser aplicados ou manipulados exclusivamente por profissional devidamente treinado ou por empresa especializada (BRASIL, 2010c), podendo ser utilizados também em campanhas de saúde pública. Segundo Papini, Andréa e Luchini (2014), os produtos saneantes desinfestantes não se referem a uma categoria diferente de grupos químicos e de ingredientes ativos específicos dos agrotóxicos aplicados na agricultura. Muitas vezes, são os mesmos ingredientes ativos e as mesmas formulações, mas para finalidade de registro, os produtos para uso em áreas urbanas são denominados desinfestantes (PAPINI; ANDRÉA; LUCHINI, 2014). Além disso, os resíduos de saneantes desinfestantes são classificados como resíduos de serviços de saúde do Grupo B pela Resolução da Diretoria Colegiada-RDC $n^{\circ}$ 222/2018 da Anvisa (BRASIL, 2018).

Igualmente aos agrotóxicos das culturas agrícolas, o uso dos saneantes desinfestantes de venda restrita gera como resíduos sólidos as embalagens pós-consumo que, se descartadas de maneira inadequada, representam riscos à saúde humana e à qualidade ambiental. Conforme a Política Nacional de Resíduos Sólidos (PNRS), Lei Federal no 12.305/2010, os agrotóxicos, seus resíduos e embalagens, assim como outros produtos cuja embalagem, após o uso, constitua resíduo perigoso, devem obrigatoriamente ser manejados pelo sistema de logística reversa (BRASIL, 2010a). A Resolução RDC $n^{\circ}$ 52/2009 da Anvisa, norma que regulamenta 0 funcionamento das empresas especializadas no controle de pragas urbanas, estabelece que as embalagens de saneantes desinfestantes de venda restrita devem ser devolvidas aos estabelecimentos onde foram adquiridas ou em postos ou centrais de recebimento por eles conveniados e previamente licenciado (BRASIL, 2009). Porém, antes da devolução, é obrigatório retornar a embalagem ao estabelecimento para submeter, as que são laváveis, à tríplice lavagem, e as que não apresentam solubilidade em água não devem passar por tríplice lavagem, devendo ser seguidas a orientação do fabricante $e$ as legislações vigentes (BRASIL, 2009).

Conforme Barreira e Philippi Junior (2002), o problema que envolve o descarte correto de agrotóxicos, seja por meio da reciclagem ou incineração, está concentrado no produto contido nas embalagens caso estas não sofram a tríplice lavagem como recomendado na legislação.

Segundo Gouveia (2012), embora tenha havido progresso nos últimos vinte anos, boa parte dos resíduos gerados não possui destinação sanitária e ambientalmente adequada. Mais da metade dos municípios brasileiros tem seus resíduos descartados em lixões. Dessa 
maneira, observa-se que, apesar da importância e relevância desse assunto, 0 alcance dos principais objetivos da PNRS não apresenta a evolução esperada e necessária até o momento (GALLARDO, 2017).

No caso dos RSS, Jacobi e Besen (2011) consideram que, embora as normas federais estabeleçam a necessidade de tratamento de determinadas classes de resíduos de serviços de saúde, prévios à sua disposição final, muitos municípios ainda dispõem de aterros sanitários, aterros controlados e lixões sem realizar prévio tratamento, o que representa risco à saúde pública e aos trabalhadores envolvidos nas atividades afins.

Tratando-se das embalagens vazias dos saneantes desinfestantes, uma atenção deve ser dispensada devido à sua característica de toxicidade. De acordo com Carneiro et al. (2015), os resíduos presentes em embalagens de agrotóxicos e afins, quando abandonados no ambiente ou descartados em aterros e lixões, contaminam o solo e, sob a ação da chuva, são carreados para as águas superficiais e subterrâneas.

As embalagens de saneantes desinfestantes é tema ainda pouco discutido, o que dificulta 0 conhecimento do atual cenário e a definição de estratégias para 0 adequado manejo desses resíduos. Diante desse contexto, 0 presente artigo tem como objetivo analisar os sistemas de gerenciamento das embalagens vazias de saneantes desinfestantes de uso profissional no município de Alagoinhas-BA.

\section{METODOLOGIA}

O estudo foi realizado no Município de Alagoinhas, localizado no estado da Bahia, a $108 \mathrm{~km}$ da capital baiana. De acordo com o IBGE (2017), o município possui uma população estimada de 155.979 habitantes e, em 2015, uma área territorial de $718,088 \mathrm{~km}^{2}$. Sua economia é baseada na agropecuária, indústria e setores terceirizados do comércio varejista e de serviços (NASCIMENTO et al., 2005). Foi o primeiro Município brasileiro a ter sua Política de Saneamento Ambiental construída com participação da sociedade, por meio de um processo de Conferência (MORAES et al., 2006). Adotando a classificação utilizada por Lima (1998), Braga (2005) e Stamm et al. (2013), que consideram de porte médio os municípios brasileiros com população urbana entre $100 \mathrm{mil} \mathrm{a}$ 500 mil habitantes, pode-se classificar Alagoinhas nesse porte. Stamm et al. (2013) consideram que as cidades brasileiras de porte médio têm uma posição estratégica potencial para a continuidade da desconcentração regional no Brasil. Elas contribuem para uma maior distribuição da população no sistema urbano brasileiro, têm as funções das cidades de menor porte, apresentam um maior peso econômico, e assumem a função de suprir as demandas dos produtos que não são produzidos nos centros de menor porte (STAMM et al., 2013).

Devido ao uso restrito que deve ser feito dos produtos saneantes desinfestantes de uso profissional, considerou-se como geradores desses resíduos em Alagoinhas:

I - a Secretaria Municipal de Saúde (SESAU), que tem como uma das atividades o controle da dengue por meio da aplicação de produtos químicos em situações especiais de maior risco (ALAGOINHAS, 2016); e

II - as empresas especializadas na prestação dos serviços de controle de pragas e vetores urbanos, comumente conhecidas como "Dedetizadoras", "Detetizadoras" e "Desinsetizadoras". Essas instituições são definidas pela RDC n ${ }^{\circ} 52 / 2009$ da Anvisa como pessoas jurídicas devidamente constituída, licenciadas pelos órgãos competentes da saúde e do meio ambiente para prestar serviços de controle de vetores e pragas urbanas (BRASIL, 2009).

Segundo dados da Vigilância Sanitária de Alagoinhas (VISA), considerando todas as empresas especializadas que tem ou em algum momento tiveram o Alvará Sanitário concedido pela Visa, atualmente, totalizam oito no banco de dados do respectivo órgão, estando sete em funcionamento.

A coleta e análise dos dados foram feitas a partir dos principais aspectos, fatores e parâmetros considerados relevantes sobre a temática e que orientam as ações para o cumprimento da PNRS, atendimento a outras exigências legais e orientações técnicas quanto a esses resíduos. A partir dessa análise, foram construídas seis categorias analíticas para este estudo: Capacidade Técnica, Ambiental, Operacional, Responsabilidade na PNRS, Jurídico-Institucional e Social.

Com vistas a ampliar o universo de 
informações em torno do objeto de pesquisa foram utilizadas para coleta de dados:

I- Entrevista semiestruturada: orientada por roteiros específicos e realizada com grupos estratégicos selecionados para o estudo. Esse grupo foi composto pelo Poder Público e empresas especializadas no controle de pragas e vetores urbanos em Alagoinhas (Tabela 1). $O$ intuito foi obter informações sobre comportamentos adotados, opiniões, relatos de experiência e estratégias que proporcionassem 0 conhecimento da realidade sobre o manejo, agentes, ações, informações quantitativas das embalagens, instrumentos e panorama do sistema.

Segundo Manzini (1990/1991), a entrevista semiestruturada está focalizada em um assunto sobre o qual foi elaborado um roteiro com perguntas principais, complementadas por outras questões inerentes às circunstâncias momentâneas à entrevista. Por envolver seres humanos como participantes para coleta de informações, o estudo foi submetido ao Comitê de Ética em Pesquisa (CEP), analisado e aprovado pelo CEP da Escola de Enfermagem da Universidade Federal da Bahia. Antes de iniciar a entrevista, foi explicado o objetivo do estudo para cada entrevistado, solicitada a autorização para gravação, informado que os dados serão utilizados apenas no âmbito desta pesquisa, e mantidos 0 anonimato dos participantes $e$ instituições. Para formalização da aceitação, solicitou-se ao entrevistado que assinasse o Termo de Consentimento Livre e Esclarecido (TCLE), caso aceitasse participar da entrevista.

Tabela 1: Informantes na entrevista semiestruturada no estudo das embalagens primárias de saneantes desinfestantes de uso profissional em Alagoinhas-BA. 2018

\begin{tabular}{|c|c|c|c|}
\hline Grupo & Informante & $\begin{array}{l}\text { Identificação } \\
\text { na pesquisa }\end{array}$ & $\begin{array}{l}\text { Total de } \\
\text { participante } \\
\text { por grupo }\end{array}$ \\
\hline \multirow[t]{6}{*}{ Poder Público } & $\begin{array}{l}\text { Secretário da Secretaria Municipal de } \\
\text { Desenvolvimento Econômico e Meio } \\
\text { Ambiente de Alagoinhas } \\
\text { (SEDEA) }\end{array}$ & S1 & 1 \\
\hline & Sanitarista/Farmacêutico da Sesau & S2 & 1 \\
\hline & Fiscais da SEDEA & FS1 e FS2 & 2 \\
\hline & $\begin{array}{l}\text { Coordenador do setor de controle a } \\
\text { endemias do Núcleo Regional de } \\
\text { Saúde do Nordeste } \\
\text { (NRSN) }\end{array}$ & $\mathrm{CN}$ & 1 \\
\hline & Fiscais da Sesau (Vigilância sanitária) & FV1 e FV2 & 2 \\
\hline & $\begin{array}{l}\text { Agentes de endemias - atuam na } \\
\text { aplicação/manipulação dos produtos } \\
\text { nas campanhas públicas }\end{array}$ & A1 & 2 \\
\hline \multirow{7}{*}{$\begin{array}{c}\text { Empresa } \\
\text { especializada }\end{array}$} & Responsável legal Empresa A (EA) & RA & 3 \\
\hline & Responsável legal Empresa B (EB) & $\mathrm{RB}$ & 1 \\
\hline & Responsável legal Empresa C(EC) & $\mathrm{RC}$ & 2 \\
\hline & Responsável legal Empresa D (ED) & $\mathrm{RD}$ & 3 \\
\hline & Responsável legal Empresa E (EE) & $\mathrm{RE}$ & 3 \\
\hline & Responsável legal Empresa F (EF) & RA & 0 \\
\hline & Responsável legal Empresa G (EG) & RA & 0 \\
\hline \multicolumn{3}{|c|}{ Total de entrevistados } & 21 \\
\hline
\end{tabular}

Fonte: Autoria própria (2018).

II- Análise documental: tratou-se da consulta a documentos e registros na busca de informações para análise do problema, ampliação das informações sobre 0 objeto de pesquisa e 
confronto com os outros dados obtidos. Essa consulta foi realizada nos órgãos ambiental e sanitário, e entidades especializadas geradoras dos resíduos.

III- Observação em campo: realização de visita in loco nas unidades geradoras para confronto das informações, observação dos aspectos categorizados, e comparação com o exigido na legislação e orientações técnicas.

As entrevistas foram transcritas e analisadas pela técnica análise de conteúdo, método utilizado também para as informações documentais. De acordo com Michel (2009), a proposta dessa técnica é aprofundar a análise do conteúdo das informações prestadas, procurando ver e analisar, em maior profundidade, a pertinência das respostas, a lógica, a coerência, a fidedignidade dos dados informados, eventuais distorções, omissões voluntárias, entre outros elementos não aparentes e retidos por qualquer mensagem.

Todas essas informações e o registro das observações em campo foram categorizadas de acordo com os aspectos e variáveis das categorias analíticas definidas para este estudo, e comparadas com o estabelecido na legislação e normas da Anvisa.

\section{RESULTADOS E DISCUSSÃO}

Do total das sete empresas especializadas no controle de pragas e vetores urbanos em Alagoinhas, cinco estavam em funcionamento no local informado pelos órgãos ambiental e sanitário e aceitaram o convite para participação na pesquisa. Duas inexistem identificações nos locais, não foram encontradas em atividade nos pontos, não foi obtido retorno de convite enviado por correio eletrônico, e não se alcançou sucesso nas tentativas de contato por telefone.

$\mathrm{Na}$ Secretaria de Saúde, o secretário remeteu a entrevista à Diretora da Vigilância em Saúde por considerar o conteúdo das questões específico do setor e por não apresentar propriedade com as informações devido à sua recente inserção na Secretaria. A Diretora remeteu ao sanitarista/farmacêutico do setor por considerá-lo apto a responder às perguntas, sendo ele o entrevistado como representante do Poder Público na Sesau (Tabela 1).

Para melhor abordagem, os resultados foram divididos em três tópicos, conforme o objetivo do estudo: Geração do resíduo, Sistemas de gerenciamento das embalagens das campanhas de saúde pública, e Sistemas de gerenciamento e atuação dos agentes nas empresas especializadas.

\section{Geração do resíduo}

A PNRS estabelece que na gestão e gerenciamento de resíduos sólidos deve ser observada a seguinte ordem de prioridade: não geração, redução, reutilização, reciclagem, tratamento dos resíduos sólidos e disposição final ambientalmente adequada dos rejeitos (BRASIL, 2010a).

Reduzir os resíduos na fonte geradora significa pensar nos resíduos antes mesmo que sejam gerados, ou seja, buscar formas de não os gerar e de combater o desperdício (SOUZA et al., 2015). Nos serviços de controle de pragas, podese alcançar a não geração e/ou minimização das embalagens dos saneantes desinfestantes, evitando-se desperdícios e utilizando-se, sempre que possível, de outras técnicas em substituição a substância química. Na averiguação desses indicadores, constatou-se por meio das entrevistas que, embora sejam utilizados outros métodos simultaneamente ao controle químico, na maioria dos casos, eles ainda são prioritários. A ED foi a única que destacou outro tipo de controle como eficiente, que é a utilização de algum dispositivo como tela (barreira física) para impedir o acesso das pragas nos locais.

$\mathrm{Na}$ análise da existência de desperdício de produtos, identificou-se que o uso é feito até seu completo término. Baseando-se nesse indicador, não foi considerada a existência de desperdício pelo não aproveitamento completo; no entanto, como nem todas as empresas têm o seu responsável técnico orientando as ações relacionadas à escolha da substância e sua quantidade, é possível que nessa etapa e na aplicação em campo existam desperdícios.

Por não ter obtido acesso às notas de compras (as empresas declararam ter perdido ou não exigir do fornecedor) e documentos que apresentassem dados quantitativos das embalagens geradas por estabelecimento, tais dados foram obtidos na entrevista a partir das informações do consumo dos produtos por período e, em alguns casos, também pela observação em campo da quantidade estocada. 
São geradas embalagens não laváveis do tipo plástica rígida com capacidade de $1 \mathrm{~kg}$, seringa de $30 \mathrm{~g}$, aerossol de $300 \mathrm{ml}$ e $204 \mathrm{ml}$, sachê de 20 a 50 gramas, saco de $1 \mathrm{~kg}$, plástica rígida lavável de $1 \mathrm{~L}$ e suas tampas medidoras (Figuras 1 a 3 ).

Segundo os entrevistados, a quantidade de produto utilizado e a consequente geração das embalagens podem sofrer variações de acordo com a demanda de serviço. Alguns são difíceis de estimar por serem situacionais e descontínuos, mas o controle e monitorização são os serviços de rotina e representam a maior parte das atividades das empresas. Nesses casos, existe a previsibilidade na geração de resíduos devido à sua continuidade e permanência.

Figura 1: Tipos de embalagens primárias laváveis geradas pelas empresas especializadas no controle de pragas urbanas investigadas em Alagoinhas-BA.
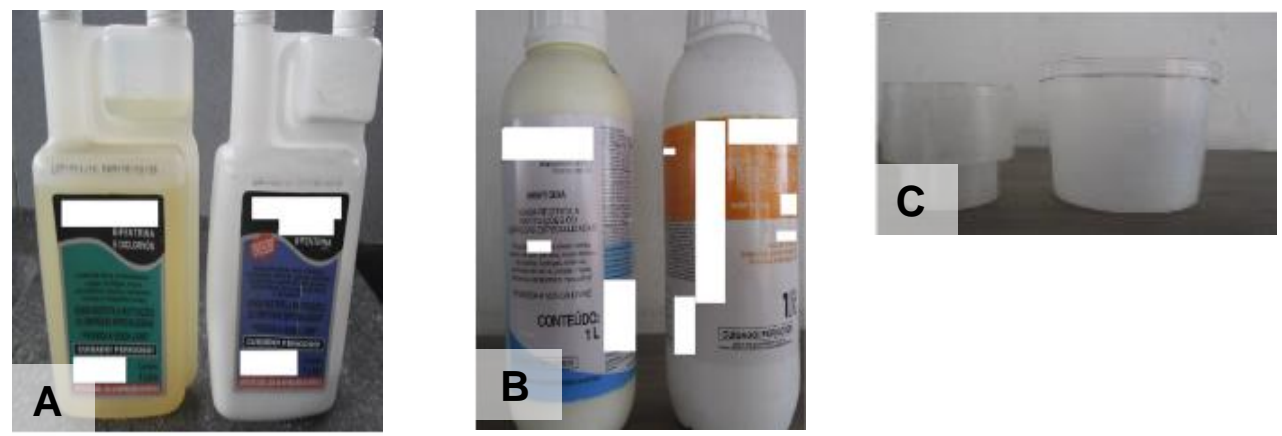

Legenda: Plástica rígida 1L (A e B) e tampas medidoras (C). Alagoinhas. 2017. Fonte: Dados da pesquisa (2017).

Figura 2: Tipos de embalagens primárias não laváveis geradas pelas empresas especializadas no controle de pragas urbanas investigadas em Alagoinhas-BA.
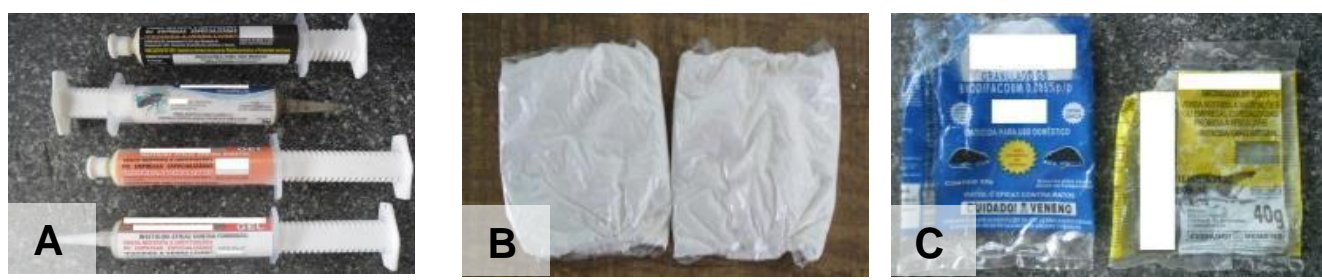

Legenda: Seringa 30g (A), sachê (B e C). Alagoinhas. 2017. Fonte: Dados da pesquisa (2017).

Figura 3: Tipos de embalagens primárias não laváveis geradas pelas empresas especializadas no controle de pragas urbanas investigadas em Alagoinhas-BA.
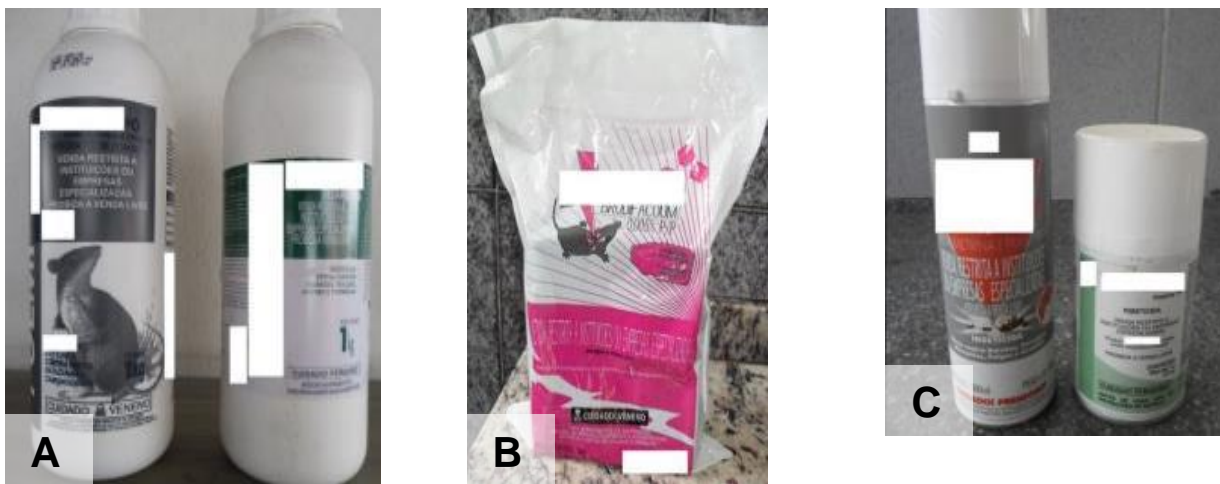

Legenda: Vasilhame $1 \mathrm{~kg}(\mathrm{~A})$, saco $1 \mathrm{~kg}(\mathrm{~B})$ e aerossol de $300 \mathrm{ml}$ e $204 \mathrm{ml}$ (C). Alagoinhas. 2017. Fonte: Dados da pesquisa (2017). 
Considerando a geração de resíduos dos serviços contínuos (que foi possível estimar), constatou-se que os recipientes gerados em maior quantidade são os sachês e sacos, que totalizam 459 unidades/mês. Em menor quantidade, são geradas as embalagens plásticas rígidas não laváveis com 13 unidades/trimestre (Tabela 2). Medida a massa $(\mathrm{kg})$ de cada embalagem e calculada a geração de todas por trimestre, totalizou-se $22,29 \mathrm{~kg}$ de recipientes gerados durante 0 período, sendo $6,84 \mathrm{~kg}$ $(30,68 \%)$ representados pelas laváveis e $15,45 \mathrm{~kg}$ $(69,32 \%)$ as não laváveis (Tabela 2 ).

A maior representatividade de embalagens não laváveis desfavorece iniciativas voltadas à reciclagem e à reinserção da matéria no ciclo produtivo, como ocorre no sistema dos agrotóxicos em que cerca de $90 \%$ do material recebido pelo Instituto Nacional de Processamento de Embalagens Vazias (INPEV) são embalagens passíveis de reciclagem, e retornam ao ciclo produtivo como matéria-prima. As embalagens não laváveis ou que não foram corretamente lavadas pelos agricultores representam cerca de $5 \%$ do total comercializado, e são encaminhadas para incineradores credenciados (INPEV, 2017).

Todos os entrevistados das empresas especializadas relataram a falta de controle no setor de manejo de pragas urbanas na cidade, e na comercialização das substâncias. Afirmaram que os produtos de uso profissional são vendidos livremente sem critérios, e que pessoas físicas (popularmente conhecidas no ramo como "Zé bombinha") e jurídicas atuam de maneira ilegal por não serem habilitadas. Tudo isso tem implicações no gerenciamento das embalagens, pois significa geração de resíduos por canais clandestinos e que dificilmente terá destinação adequada.

\section{Tabela 2 Quantidade (unidade) de embalagens primárias de saneantes desinfestantes de uso profissional por tipo, de acordo com o consumo, das empresas especializadas no controle de pragas urbanas em Alagoinhas-BA. 2017}

\begin{tabular}{|c|c|c|c|c|c|}
\hline \multirow{2}{*}{$\begin{array}{r}\text { Tipos de } \\
\text { Embalagens }\end{array}$} & \multirow[b]{2}{*}{$\begin{array}{c}\text { Plástica } \\
\text { rígida lavável }\end{array}$} & \multicolumn{4}{|c|}{ Não laváveis } \\
\hline & & Aerossol & Seringa & $\begin{array}{l}\text { Plástica } \\
\text { rígida não } \\
\text { lavável }\end{array}$ & $\begin{array}{c}\text { Sachê e/ou } \\
\text { saco }\end{array}$ \\
\hline$A$ & 5/mês & 5/mês & 5/mês & $1 /$ mês & 138/mês \\
\hline B & $5 /$ mês & $\begin{array}{c}\text { Não } \\
\text { utiliza }\end{array}$ & 30/mês & $1 /$ trimestre & 35/mês \\
\hline $\mathrm{C}$ & 3/mês & 4/mês & 10/mês & 1/mês & 122/mês \\
\hline$D$ & 3/mês & 4/mês & 4/mês & $1 /$ mês & $81 /$ mês \\
\hline$E$ & 3/mês & 2/mês & 20/mês & 1/mês & 83/mês \\
\hline Total (unidade) & 19/mês & 15/mês & 69/mês & 13/trimestre & 459/mês \\
\hline \multirow{2}{*}{ Total (kg) } & $6,84 \mathrm{~kg}$ & \multicolumn{4}{|c|}{$15,45 \mathrm{~kg}$} \\
\hline & \multicolumn{5}{|c|}{$22,29 \mathrm{~kg}$} \\
\hline
\end{tabular}

Fonte: Dados da pesquisa (2018).

No caso dos saneantes desinfestantes de venda restrita utilizados nas campanhas de saúde pública, são indicados pelo Ministério da Saúde e encaminhados para serem distribuídos pelos Núcleos Regionais de Saúde (NRS) aos municípios, por meio das vigilâncias epidemiológicas. Em Alagoinhas, o NRS é o Núcleo Regional de Saúde do Nordeste (NRSN), localizado na própria cidade e que abrange 33 municípios da Bahia. As embalagens rotineiramente geradas no Município são os sachês de $100 \mathrm{~g}$ do pyriproxifen para o tratamento focal (tratamento dos criadouros do mosquito), e, em menor frequência, recipientes de plásticos rígidos laváveis dos produtos líquidos utilizados para tratamentos específicos e eventuais. Segundo dados do Coordenador do setor de controle a endemias do NRSN (CN), a 
distribuição dos produtos é feita para 18 municípios, e as embalagens armazenadas e destinadas correspondem ao montante dessas localidades. São geradas embalagens primárias de saneantes desinfestantes de uso restrito do tipo plásticas laváveis rígidas de $1 \mathrm{~L}$ e de $20 \mathrm{~L}$, plástica rígida não lavável de $500 \mathrm{~g}$, e sachê de 100 gramas (Figura 4).

\section{Figura 4: Embalagens primárias de saneantes desinfestantes de uso restrito gerados nas} campanhas de saúde pública nos municípios abrangidos pelo NRSN.
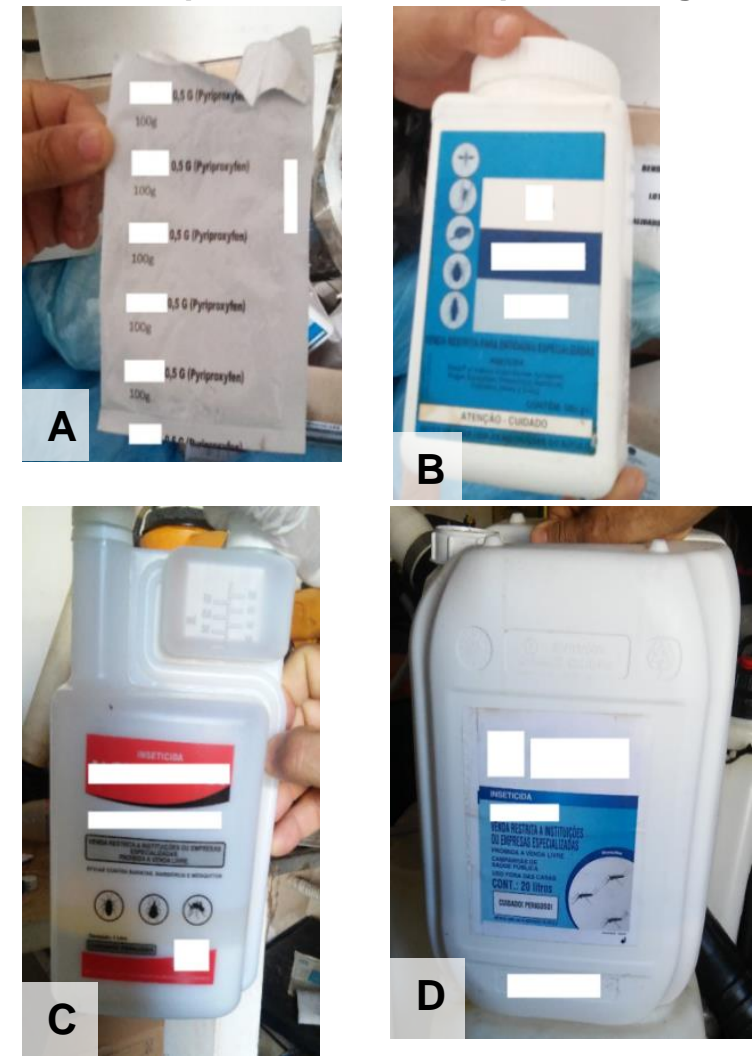

Legenda: Não laváveis: Sachê $100 \mathrm{~g}$ (ingrediente ativo pyriproxifen) (A) e plástica rígida de $500 \mathrm{~g}$ (ingrediente ativo bendiocarbe) (B). Laváveis: plástico rígido $1 \mathrm{~L}$ (ingrediente ativo alfacipermetrina) (C), plástica rígida de $20 \mathrm{~L}$ (ingrediente ativo malationa) (D). Alagoinhas. 2018. Fonte: Dados da pesquisa (2018).

\section{Sistemas de gerenciamento e atuação dos agentes nas empresas especializadas}

Nas etapas do manejo, diferentes cenários foram encontrados nas empresas especializadas no controle de pragas urbanas em Alagoinhas (Figura 5). As ações puderam ser averiguadas por meio das entrevistas, análise documental e observação em campo em algumas empresas.

As embalagens laváveis devem ser submetidas à tríplice lavagem antes de sua devolução, devendo a água ser reaproveitada para o preparo de calda ou inativada, conforme instruções contidas na rotulagem ou por orientação técnica do fabricante do produto e do órgão competente (BRASIL, 2009). Esse procedimento capaz de reduzir o nível de contaminação das embalagens não faz parte da rotina de todas as empresas. Dentre as cinco investigadas, a realização da tríplice lavagem foi relatada por EA, EB, EC e EE. Na EA, foi relatada por apenas um dos dois funcionários, e em EC, o responsável e o funcionário afirmaram não realizar logo após o esvaziamento da embalagem. A importância de se realizar a tríplice lavagem imediatamente após o esgotamento do produto é para facilitar a remoção, aproveitar ao máximo o conteúdo do líquido e evitar que resseque e fique aderido nas paredes da embalagem, dificultando o processo de remoção dos resíduos internos (ZÜGE et al., 2009).

Pavarini e Pavarini (2012) consideram que a tríplice lavagem das embalagens vazias de agrotóxicos, antes do seu descarte, torna-se, 
quando realizada de forma eficiente, uma das práticas para a solução da disposição pós-uso das embalagens para a maioria dos produtos acondicionados em embalagens plásticas rígidas, pois trata de uma operação comprovadamente eficaz na eliminação de resíduo de agrotóxico. Barreira e Philippi Junior (2002) destacam que a preocupação constante de especialistas na área ambiental e de saúde pública está justamente na saúde do trabalhador que opera a recicladora, pois a única maneira que os operadores percebem se a embalagem está contaminada é extremamente subjetiva, ou seja, por meio do contato visual e olfativo, contribuindo para mais um problema de saúde pública.
Em nenhuma das empresas foi identificado problema quanto ao tipo de recipiente utilizado para acondicionamento das embalagens vazias. Acondicionam em saco plástico, balde de 60L ou na própria caixa de papelão. No entanto, todas as empresas declararam não segregar as laváveis das não laváveis por acreditarem que receberiam o mesmo destino, embora essa informação nunca tenha sido solicitada a quem as destinam. Os resíduos classe II não devem ser armazenados juntamente com resíduos classe I, em face da possibilidade da mistura resultante ser caracterizada como resíduo perigoso (ABNT, 1990).

\section{Figura 5: Fluxograma do manejo informado e/ou averiguado nas empresas especializadas no controle de pragas em Alagoinhas. 2017}

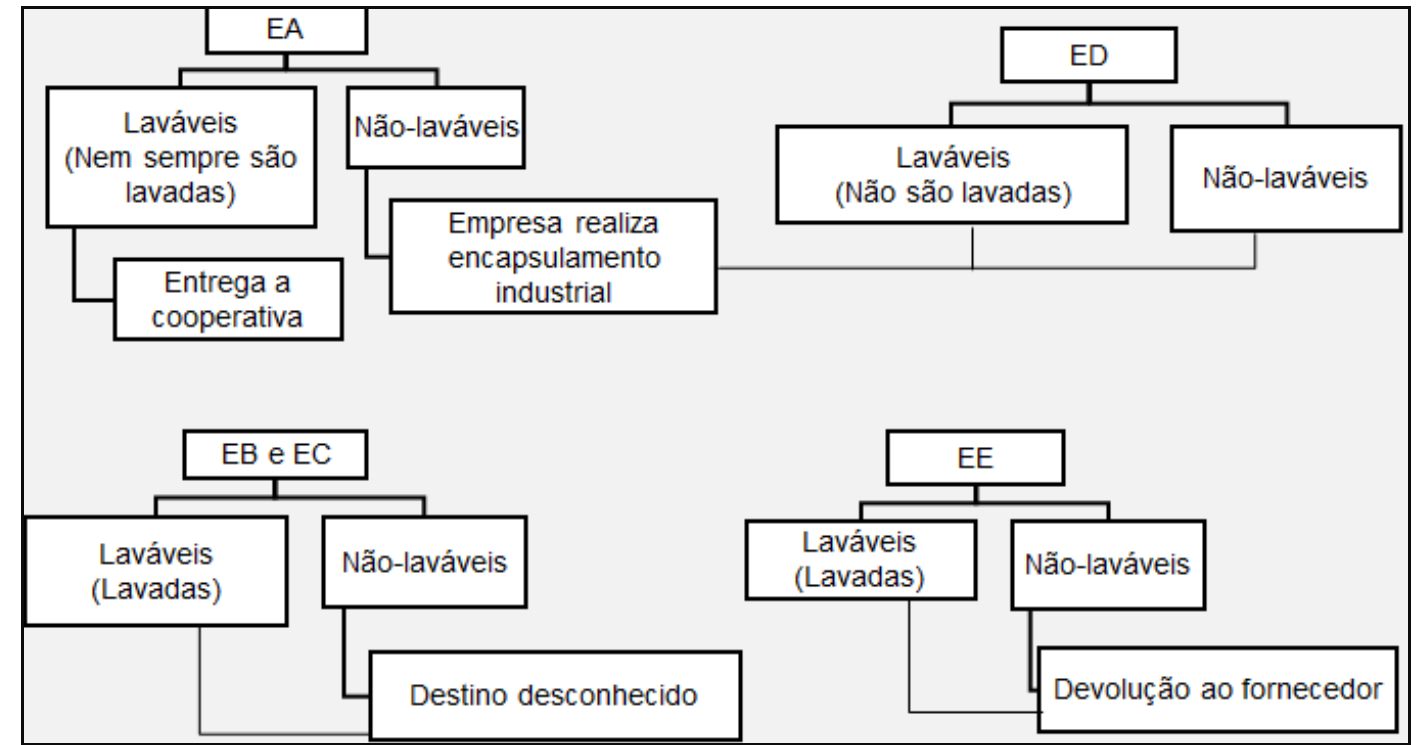

Fonte: Autoria própria (2018).

Todas as empresas investigadas afirmaram que já tiveram o interesse em devolver as embalagens ao local onde foram adquiridas, no entanto, com exceção da EE, as demais relataram que os comerciantes não as recebem. A justificativa da recusa é por não possuírem local para estocá-las, não terem como se responsabilizar pela destinação e logística, ou pela inviabilidade de arcarem com o custo para destinação. Nessas condições, os consumidores são orientados a buscar, individualmente, outras alternativas. A persistente resistência do setor empresarial em implementar programas de logística reversa, mesmo quando a legislação assim o exige, é um dos primeiros desafios para a concretização da logística reversa citado por Demajorovic et al. (2014). Mesmo diante dessa postura dos fornecedores, as empresas investigadas afirmam continuar adquirindo produtos com estes porque oferecem melhores preços e forma de entrega.

Quanto ao destino final das embalagens primárias vazias de saneantes desinfestantes de uso profissional, diferentes sistemas foram identificados. $\mathrm{Na} \mathrm{EA}, \mathrm{O}$ responsável legal informou que as plásticas rígidas são coletadas por uma cooperativa local e encaminhadas para reciclagem na cidade de Feira de Santana-BA, e os demais tipos de embalagens não recicláveis 
ou recicláveis que não tenham sido coletados pelos cooperados são transportados a Feira de Santana (distância aproximada de $80 \mathrm{~km}$ ) por uma empresa habilitada $(\mathrm{ET})$ que, conforme o contrato de prestação de serviço, realiza 0 encapsulamento industrial. $\mathrm{Na} E B$ e EC, os responsáveis informaram que todas as embalagens são coletadas por ET para serem incineradas; no entanto, os contratos dos serviços de coleta estão com validade ultrapassada, e o destino considerado neste estudo foi como "desconhecido" (Figura 5).

Em ED, foi informado por RD e verificado em documentos que há aproximadamente dois anos firmou-se contrato com ET para coleta e destinação final das embalagens, porém, ainda não se alcançou volume considerável para realização da coleta. $\mathrm{Na} \mathrm{EE}$, foi verificada a declaração de devolução e informado pelo seu responsável que as embalagens são devolvidas ao local onde foram adquiridas na capital.

Foram analisados cinco Planos de Gerenciamento de Resíduos Sólidos (PGRS), em que se verificou a insuficiência de informações para 0 diagnóstico da situação e, consequentemente, carência de orientações, como a tríplice lavagem e segregação na fonte dos diferentes tipos de resíduos gerados. O destino/sistema orientado nos planos foi a logística reversa das embalagens de saneantes desinfestantes ou seu encaminhamento para incineração (Quadro 1).

\section{Quadro 1: Resumo do cenário encontrado nas empresas especializadas no controle de pragas em Alagoinhas, quanto ao gerenciamento das embalagens de saneantes desinfestantes de uso profissional, 2018.}

\begin{tabular}{|c|c|c|c|c|c|c|}
\hline Empresa & $\begin{array}{c}\text { Segregação } \\
\text { na fonte }\end{array}$ & $\begin{array}{c}\text { Tríplice } \\
\text { lavagem das } \\
\text { embalagens } \\
\text { laváveis }\end{array}$ & $\begin{array}{l}\text { Devolução } \\
\text { ao } \\
\text { fornecedor }\end{array}$ & $\begin{array}{c}\text { Situação do } \\
\text { PGRS }\end{array}$ & $\begin{array}{c}\text { Destinação } \\
\text { orientada } \\
\text { no PGRS }\end{array}$ & $\begin{array}{l}\text { Participação em } \\
\text { algum } \\
\text { Programa } \\
\text { relacionado às } \\
\text { embalagens }\end{array}$ \\
\hline A & Não & $\begin{array}{c}\text { Nem sempre } \\
\text { realiza }\end{array}$ & Não & \multirow{5}{*}{$\begin{array}{c}\text { Ausência de } \\
\text { informações } \\
\text { sobre todos } \\
\text { os tipos de } \\
\text { embalagens } \\
\text { geradas, } \\
\text { orientações } \\
\text { específicas } \\
\text { para tipo, e } \\
\text { sua } \\
\text { quantidade } \\
\text { por período }\end{array}$} & $\begin{array}{l}\text { Logística } \\
\text { reversa }\end{array}$ & Não participa \\
\hline$B$ & Não & Sim & Não & & Incineração & Não participa \\
\hline C & Não & $\begin{array}{l}\text { Não realiza de } \\
\text { imediato após o } \\
\text { término }\end{array}$ & Não & & Incineração & Não participa \\
\hline D & Não & Sim & Não & & $\begin{array}{c}\text { Logística } \\
\text { reversa }\end{array}$ & Não participa \\
\hline $\mathrm{E}$ & Não & Sim & Sim & & $\begin{array}{c}\text { Logística } \\
\text { reversa }\end{array}$ & Não participa \\
\hline
\end{tabular}

Fonte: Dados da pesquisa (2018).

Em alguns municípios do País, está sendo implantado pela Associação Brasileira de Aerossóis e Saneantes Domissanitários (ABAS), com a participação de 16 fabricantes de produtos saneantes desinfetantes, o Programa Cidade Sustentável (PCS). O PCS tem o intuito de promover 0 recebimento dessas embalagens vazias que foram comercializadas nos estados abrangidos pelo Programa (ABAS, 2017). Conforme o responsável pelo gerenciamento do PCS, atualmente, está em fase de reestruturação, sendo que na Bahia são atendidas três cidades: Salvador e Feira de Santana com um ponto fixo de recebimento cada, e Lauro de Freitas com dois. Existem também os pontos volantes, que são as coletas agendadas quando há necessidade em algum local que não tem demanda suficiente para ser um ponto fixo. Nesse caso, as devoluções são feitas no próprio caminhão da empresa contratada pelo Programa.

Analisando os locais de recebimento, percebe-se que Feira de Santana é o ponto mais 
próximo de Alagoinhas, porém, 0 ato está vinculado à compra, ou seja, para que o distribuidor receba as embalagens, é necessário que os produtos tenham sido adquiridos no local da entrega e sejam de fabricantes participantes do Programa. Nem sempre é viável para a empresa especializada no controle de pragas o deslocamento para aquisição de produto em outra cidade, assim como a escolha do fornecedor é baseada nos melhores preços, forma de pagamento, entrega e disponibilidade do produto procurado. $\mathrm{O}$ recebimento das embalagens pósconsumo não é utilizado como critério para a escolha do fornecedor.

Até o momento, os pontos de recebimento cadastrados no PCS são os próprios distribuidores dos produtos, os quais utilizam suas instalações para a estocagem temporária. Em Alagoinhas, ainda não existem cadastrados como ponto fixo nem ponto volante. Dentre todos os entrevistados das empresas especializadas e do Poder Público municipal, apenas EA têm conhecimento da existência do PCS. Há um distribuidor de Salvador participante do Programa e que atua em Alagoinhas, no entanto, os produtos devem ter sido adquiridos em seu estabelecimento e sejam dos fabricantes participantes, e as embalagens devem ser entregues na capital.

A questão do custo com transporte é emblemática da dificuldade que é avançar o modelo brasileiro de logística reversa, de forma a atender alguns dos principais objetivos da PNRS (DEMAJOROVIC; AUGUSTO; SOUZA, 2016). Esse tipo de obstáculo foi verificado também por Cometti e Alves (2010) para devolução das embalagens de agrotóxicos:

Nos bastidores do sistema desenvolvido pelos fabricantes existem comerciantes e agricultores que arcam com os custos de entregar as embalagens vazias de agrotóxicos apenas nos postos e centrais de recebimento, estabelecidos pelo inpEV. Os fabricantes ignoraram a legislação, que estabelece que as unidades de recebimento devem ter operacionalização e localização que facilitem a devolução das embalagens pelos agricultores. $\mathrm{O}$ descumprimento do Art. 57 do Decreto no 4.074/2002 não está sendo observado pelos órgãos governamentais, responsáveis pela fiscalização do sistema de destinação final das embalagens (COMETTI; ALVES, 2010, p. 20).

No caso das embalagens dos saneantes desinfestantes, diante dos dados analisados, observa-se também que o PCS ainda não ganhou a mesma força e participação como no caso do programa de devolução das embalagens vazias dos agrotóxicos. A responsabilidade, na maioria dos casos observados, continua sendo integralmente do consumidor, que são as empresas especializadas no controle de pragas e vetores urbanos. Por diversos fatores, entre eles econômicos, locacionais e estruturais, torna-se mais exequível ao fabricante, diretamente ou por meio dos seus distribuidores, realizar essa destinação adequada, seja inserindo como matéria-prima no seu ciclo produtivo, ou promovendo outra destinação permitida em lei. Essa compreensão do problema não é concebida pelos consumidores dos produtos, e menos ainda pelos comerciantes.

\section{Sistemas de gerenciamento das embalagens das campanhas de saúde pública}

No caso das embalagens dos saneantes desinfestantes de uso profissional utilizados nas campanhas de saúde pública em Alagoinhas, segundo o $\mathrm{CN}$, as plásticas rígidas laváveis são mantidas no NRSN, e cada órgão municipal responsável pelo combate a endemias reutiliza uma embalagem para adquirir produto, quando necessário. Quando se tornam inutilizáveis, os recipientes de cada município são devolvidos ao NRSN sem a realização da tríplice lavagem. A entrega do produto em sachê à Visa é limitada à quantidade de $20 \mathrm{~kg}$ por bimestre, e somente são entregues quando as embalagens pós-consumo dos produtos anteriores são devolvidas. Com base em dados de coletas anteriores, estimam que somente em Alagoinhas sejam gerados $3 \mathrm{~kg}$ de embalagens a cada bimestre, ou seja, $18 \mathrm{~kg}$ anual. A existência do controle na distribuição e da condição de devolução da embalagem para a entrega de novos produtos pode evitar desperdícios e descarte inadequado pelos órgãos responsáveis pela aplicação do produto no Secretaria de Saúde do Estado da Bahia Município.

A tríplice lavagem não é um procedimento realizado pela Visa nem pelo NRSN. Todas as 
embalagens pós-consumo são armazenadas em depósito único nas instalações do NRSN (Figura 6), sendo os sachês acondicionados em sacos, as plásticas rígidas laváveis e não laváveis em caixa de papelão e os galões de 20L individualmente empilhados. Todas as embalagens são coletadas por uma empresa contratada pela (SESAB) para a coleta destas e de outros resíduos gerados pelas demais Unidades da Sesab. O órgão acionado para solicitação da coleta é a Diretoria de Vigilância Epidemiológica (DIVEP/SESAB), situada na capital do estado, a qual deve ser informada com antecedência a iminente necessidade da coleta, para averiguação da existência de contrato vigente com uma empresa de transporte.

A viabilidade da coleta no NRSN depende da quantidade de resíduos estocados, e por isso não há uma periodicidade determinada. CN estimou ser necessária uma quantidade mínima de $500 \mathrm{~kg}$ de embalagens para que esse Núcleo seja incluído como um ponto na rota. Considerando que o NRSN contempla 18 municípios, a previsão do órgão é de que essa quantia seja alcançada em um ano, somando-se todos os tipos de embalagens. Quando da realização da pesquisa, a quantidade já havia sido atingida e a Divep acionada, porém, estavam em andamento os trâmites administrativos para contratação de nova empresa de transporte, e os resíduos permaneciam estocados. A última coleta foi realizada em 2016, e o destino informado para essas embalagens contaminadas foi a incineração.

\section{Figura 6: Depósito de armazenamento das embalagens de produtos saneantes desinfestantes de uso restrito utilizados nos municípios abrangidos pelo NRSN. Alagoinhas. 2018}

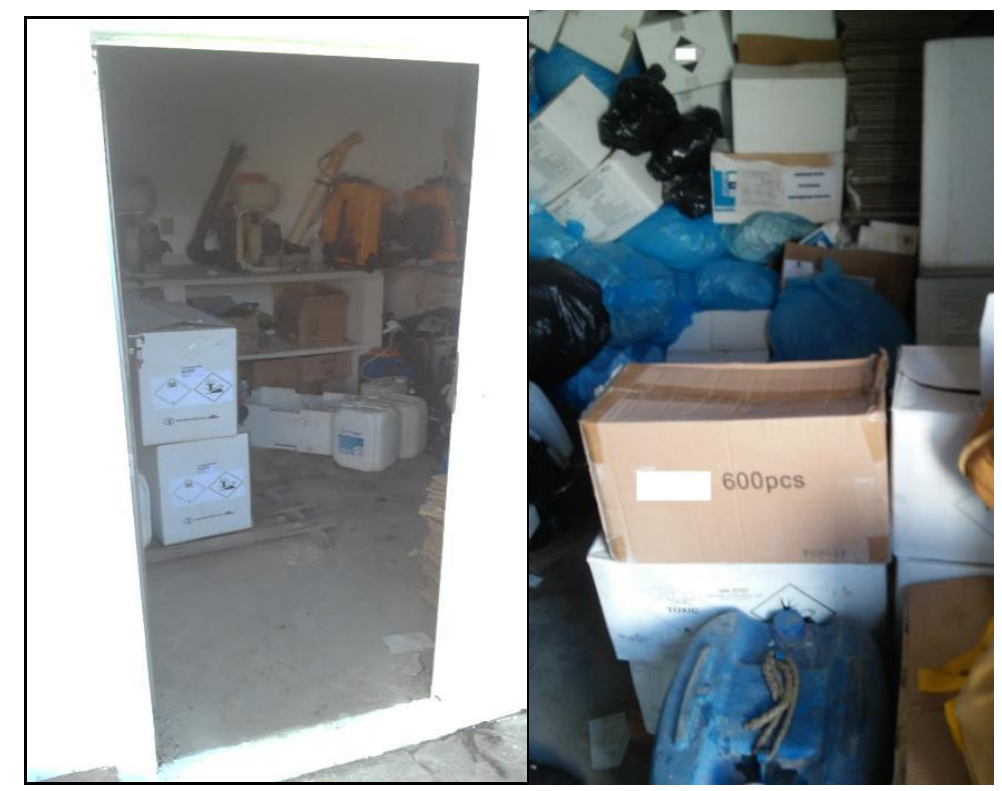

Fonte: Banco de fotos da primeira autora (2018).

Embora nas campanhas de saúde pública em Alagoinhas sejam geradas embalagens passíveis de serem submetidas à tríplice lavagem - um procedimento que deve ser realizado imediatamente após o esgotamento do produto (ZÜGE et al., 2009), no NRSN, esse procedimento é impossibilitado. Como principais obstáculos podem ser citados: a falta de instalação apropriada para lavagem; a incerteza da utilização da calda da lavagem dentro do prazo de validade do produto, visto que são substâncias utilizadas em casos excepcionais (não rotineiros); e o perigo envolvido no provável armazenamento da calda no depósito que se encontra em condição insalubre (Figura 5), o que aumentariam os riscos de acidente e consequente contaminação, já que a calda representa um volume maior de líquido que o resíduo do produto na embalagem. Conforme relatado por $\mathrm{CN}$, a realização da tríplice lavagem 
representaria riscos maiores de contaminação ao ambiente e saúde do funcionário.

No armazenamento e destinação das embalagens, não há segregação quanto ao município de origem e tipo de embalagem, fator que dificultou a obtenção de informações sobre a porcentagem que representa as embalagens geradas apenas por Alagoinhas. Mas, de acordo com $\mathrm{CN}$, as plásticas rígidas laváveis correspondem à menor parcela do total da massa (kg) de resíduos gerados.

A periculosidade do resíduo e o período consideravelmente longo que as embalagens permanecem estocadas tornam-se uma situação problema se não adotados os cuidados necessários, como o armazenamento em local adequado. O NRSN não se trata de uma central de recebimento a qual deve passar por um licenciamento, porém, os critérios mínimos devem ser atendidos a fim de garantir a segurança. Foi verificado no local um ambiente repleto de embalagens vazias contaminadas acondicionadas em caixas e sacos, ausência de ventilação e liberação de forte odor característico dos produtos. Assim como um depósito/galpão para o armazenamento de embalagens vazias de agrotóxicos, um fator importante no armazenamento é a temperatura no interior do mesmo. As temperaturas mais altas podem provocar o aumento da pressão interna nos frascos, contribuindo para a ruptura da embalagem, ou mesmo propiciando o risco de contaminação de pessoas durante a abertura da mesma.

\section{CONCLUSÃO}

As embalagens primárias de saneantes desinfestantes de uso profissional ainda não são alvo de preocupação, como os agrotóxicos e demais tipos de Resíduos de Serviços de Saúde, e muitos desafios puderam ser evidenciados para sua gestão e adequado gerenciamento.

Observou-se a necessidade da execução de procedimentos e etapas intra-estabelecimento importantes, como a realização da tríplice lavagem e a segregação na fonte, para a adequada destinação final das embalagens de saneantes desinfestantes de uso profissional.

A maior representação de embalagens não recicláveis é um fator que deve ser repensado pelo fabricante e consumidores, pois um dos objetivos da PNRS é o estímulo à adoção de padrões sustentáveis de produção e consumo de bens e serviços, e o da Responsabilidade Compartilhada é o estímulo ao desenvolvimento de mercado, a produção e o consumo de produtos derivados de materiais reciclados e recicláveis.

A implementação da logística reversa encontra obstáculos semelhantes aos enfrentados no manejo das embalagens de agrotóxicos em pequenas comunidades rurais, os quais se referem ao aspecto operacional relacionado ao transporte. O critério quantitativo geralmente utilizado para viabilizar os deslocamentos para a coleta pode impossibilitar a etapa do transporte, pois a quantidade gerada pelo município pode não justificar esse custo.

O princípio da responsabilidade compartilhada estabelecido na PNRS não foi assimilado por todos os envolvidos no ciclo de vida do produto, o que resulta na falta da execução dos papéis pelos agentes, principalmente pelos revendedores/comerciantes no recebimento das embalagens e no controle da comercialização dos produtos.

A existência do Programa Cidade Sustentável apoiado por fabricantes dessas substâncias é uma alternativa para melhor gestão e gerenciamento desses resíduos, no entanto, é necessário buscar interação para que os agentes possam garantir que essas embalagens retornem no fluxo reverso de maneira adequada e segura.

Assim como houve com os agrotóxicos, torna-se necessária maior divulgação dos programas e sistemas existentes dos fabricantes. A criação de pontos volantes, conforme modelo adotado pelo Programa Cidade Sustentável em locais onde não há demanda de resíduos para se tornar um ponto fixo, pode ser uma alternativa para Alagoinhas. Por não ser um projeto de grande retorno econômico ou visibilidade numa gestão local que mobilize esforços maiores do Poder Público, para sua implementação e sucesso, serão necessários iniciativa e empenho, principalmente dos comerciantes e empresas especializadas.

O Poder Público ainda não consegue ter o efetivo controle das atividades do setor de controle de pragas no município, e isso tem implicações na gestão e gerenciamento das embalagens dos saneantes desinfestantes. Observou-se que carece de maior rigor na análise 
dos documentos referente a esses resíduos e no acompanhamento das ações.

A coleta e análise das informações limitaramse àquelas que foram possíveis de prospectar e sistematizar no mercado legal e junto ao Poder Público. Conforme relato dos entrevistados, existe um mercado clandestino, o qual não foi o alvo deste estudo, mas que tem implicações diretas na gestão e gerenciamento das embalagens de saneantes desinfestantes de uso profissional por serem fontes de canais clandestinos da geração desses resíduos perigosos, e que dificilmente receberão destinação adequada.

Diante dos resultados, evidencia-se a necessidade de estudos que abordem estratégias para facilitar a operacionalização na devolução das embalagens, alcançando de forma eficiente todas as empresas especializadas no controle de pragas urbanas e o Poder Púbico (ambos geradores desses resíduos), em especial os situados nas localidades longínquas dos fornecedores e das capitais. Faz-se necessária, também, uma análise das possibilidades e dos obstáculos para a inserção regularizada de cooperativas/associação locais de catadores de materiais recicláveis no ciclo de vida das embalagens de saneantes desinfestantes recicláveis que estejam lavadas, tendo em vista os objetivos da PNRS e a importância ambiental e social dessas organizações.

\section{REFERÊNCIAS}

ALAGOINHAS. Alagoinhas implanta o Sistema Estadual de Informações Ambientais e Recursos Hídricos. 2016. Disponível em:< https://www.alagoinhas.ba.gov.br/index.php/alagoinhasimplanta-o-sistema-estadual-de-informacoes-

ambientais-e-recursos-hidricos/>. Acesso em: 04 jun. 2018.

ASSOCIAÇÃO BRASILEIRA DE AEROSSÓIS E SANEANTES DOMISSANITÁRIOS- ABAS. Cidade Sustentável - Embalagens Vazias. Resumo. 2017. Disponível em:< http://www.as.org.br/embalagem.htm >. Acesso em: 23 jun. 2018.

ASSOCIAÇÃO BRASILEIRA DE NORMAS TÉCNICAS - ABNT. NBR 11.174: Armazenamento de resíduos classes II - não inertes e III - inertes. Rio de Janeiro, 1990.

BARREIRA, L. P.; PHILIPPI JUNIOR, A. Problemática dos resíduos de embalagens de agrotóxicos no Brasil. In: CONGRESO INTERAMERICANO DE INGENIERÍA
SANITARIA Y AMBIENTAL, 28., 2002, Cancun. Anais... Cancun: AIDIS, 2002. 1 CD-ROM.

BRAGA, R. Cidades médias e aglomerações urbanas no Estado de São Paulo: novas estratégias de gestão territorial. In: ENCONTRO DE GEÓGRAFOS DA AMÉRICA LATINA, 10., 2005, São Paulo. Anais... São Paulo: AGB, 2005. p. 2241-2254.

BRASIL. Resolução da Diretoria Colegiada RDC $n^{\circ}$ 222, de 29 de março de 2018/ ANVISA - Agência Nacional de Vigilância Sanitária. Regulamenta as Boas Práticas de Gerenciamento dos Resíduos de Serviços de Saúde e dá outras providências. Diário Oficial da União, Brasília, DF, 29 mar. 2018. Seção 1, p. 228233.

BRASIL. Lei no. 12.305, de 02 de Agosto de 2010. Institui a Política Nacional de Resíduos Sólidos Institui a Política Nacional de Resíduos Sólidos; altera a Lei $n$ 9.605, de 12 de fevereiro de 1998; e dá outras providências. Diário Oficial da União, Brasília, DF, 03 ago. 2010. Seção 1, p. 3-7. 2010a.

BRASIL. Resolução da Diretoria Colegiada RDC no 34 de 16 de agosto de 2010 / ANVISA - Agência Nacional de Vigilância Sanitária. Dispõe sobre o Regulamento Técnico para produtos saneantes desinfestantes. Diário Oficial da União no 158, Brasília, DF, 18 ago. 2010. Seção 1, p. 42-44. 2010b.

BRASIL. Resolução da Diretoria Colegiada RDC no 52 de 22 de outubro de 2009 / ANVISA - Agência Nacional de Vigilância Sanitária. Dispõe sobre o funcionamento de empresas especializadas na prestação de serviço de controle de vetores e pragas urbanas e dá outras providências. Diário Oficial da União no 204, Brasília, DF, 26 out. 2009. Seção 1, p. 61-62.

BRASIL. Resolução da Diretoria Colegiada RDC no 59 de 17 de dezembro de 2010 / ANVISA - Agência Nacional de Vigilância Sanitária. Dispõe sobre os procedimentos e requisitos técnicos para a notificação e o registro de produtos saneantes e dá outras providências. Diário Oficial da União no 244, Brasília, DF, 22 dez. 2010. Seção 1, p. 80-82. 2010c.

CARNEIRO, F. F.; RIGOTTO, R. M.; AUGUSTO, L. G. S.; BÚRIGO, A. C. Dossiê ABRASCO: um alerta sobre os impactos dos agrotóxicos na saúde. Rio de Janeiro: EPSJV; São Paulo: Expressão Popular, 2015. cap. 2, p. 90-190.

COMETTI, J. L. S.; ALVES, I. T. G.. Responsabilização pós-consumo e logística reversa: o caso das embalagens de agrotóxicos no Brasil. Sustentabilidade em Debate, v. 1, n. 1, p. 13-24, 2010. 
DEMAJOROVIC, J.; CAIRES, E. F.; GONÇALVES, L. N. S.; SILVA, M. J. C. Integrando empresas e cooperativas de catadores em fluxos reversos de resíduos sólidos pós-consumo: o caso Vira-Lata. Cadernos Ebape, v. 12, p. 513-532, 2014.

DEMAJOROVIC, J.; AUGUSTO, E. E. F.; SOUZA, M. T. S. Logística reversa de REEE em países em desenvolvimento: desafios e perspectivas para 0 modelo brasileiro. Ambiente \& Sociedade, São Paulo, v. 19, n. 2, p.119-138, 2016.

GALLARDO, S. M. A. G. O manejo dos resíduos sólidos nos municípios brasileiros e a situação observada no estado de São Paulo. Cadernos da Escola Paulista de Contas Públicas, Paulo, v. 1, n. 1, p. 41-49, 2017.

GOUVEIA, N. Resíduos sólidos urbanos: impactos socioambientais e perspectiva de manejo sustentável com inclusão social. Ciência \& saúde coletiva, Rio de Janeiro, v. 17, p. 1503-1510, 2012.

INSTITUTO BRASILEIRO DE GEOGRAFIA E ESTATÍSTICA - IBGE. 2017 Cidades. Disponível em:< http://www.cidades.ibge.gov.br/xtras/perfil.php?lang=\&c odmun=290070\&search=bahia|alagoinhas $>$. Acesso em: 15 mar. 2018.

INSTITUTO NACIONAL DE PROCESSAMENTO DE EMBALAGENS VAZIAS- INPEV. Relatório de Sustentabilidade 2017. Disponível em:<https://www.inpev.org.br/Sistemas/Saiba-

Mais/Relatorio/inpEV_RS2017.pdf >. Acesso em: 23 jun. 2018.

JACOBI, P. R.; BESEN, G. R. Gestão de resíduos sólidos em São Paulo: desafios da sustentabilidade. Estudos avançados, São Paulo, v. 25, n. 71, p. 135158, 2011.

LIMA, R. S. Expansão urbana e acessibilidade: o caso das cidades médias brasileiras. 1998. 81p. Dissertação (Mestrado em Engenharia Transportes, Estradas e Aeroportos) - Escola de Engenharia de São Carlos, Universidade de São Paulo, São Carlos, 1998.

MANZINI, E. J. A entrevista na pesquisa social. São Paulo: Didática, 1990/1991, v. 26/27, p.149-158.
MICHEL, M. H. Metodologia científica em ciências sociais aplicadas. 2. ed. São Paulo: Atlas, 2009. p. 66-70.

MORAES, L. R. S.; REIS, M. D. G. D. C.; ZANTA, V. M.; LUZ, L. D. D.; ORRICO, S. R. M.; MACHADO, N.; AGRA FILHO, S. S.; NASCIMENTO, S. A. DE M; SILVA, B. J. Plano municipal de saneamento ambiental de Alagoinhas, Brasil: metodologia e resultados. In: CONGRESO INTERAMERICANO DE INGENIERÍA SANITARIA Y AMBIENTAL, 30., 2006, México. Anais... São Paulo: AIDIS, 2006. p.1-13.

NASCIMENTO, S. A. M.; MORAES, L. R. S.; SANTANA, A. V. A.; REIS, M. G. de C.. Avaliação quantitativa e qualitativa das águas subterrâneas como componente do plano municipal de saneamento ambiental de Alagoinhas-BA. In: ASSEMBLEIA NACIONAL DA ASSOCIAÇÃO NACIONAL DOS SERVIÇOS MUNICIPAIS DE SANEAMENTO, 35., 2005, Belo Horizonte. Anais... Brasília: ASSEMAE, 2005. 1 CD-ROM.

PAPINI, S.; ANDRÉA, M. M.; LUCHINI, L. C. Segurança ambiental no controle químico de pragas e vetores. 1. ed. São Paulo: Atheneu, v. 1, 2014. 290p.

PAVARINI, G. M. P.; PAVARINI, R. Método didático: demonstração prática da eficiência da lavagem de embalagens vazias de agrotóxicos. Nucleus, São Paulo, v. 9, n. 2, p.1-12, 2012.

SOUZA, C. M. N.; COSTA, A. M.; MORAES, L. R. S.; FREITAS, C. M. Saneamento: promoção da saúde, qualidade de vida e sustentabilidade ambiental. Rio de Janeiro: Editora Fiocruz, 2015. 140p.

STAMM, C.; STADUTO, J.; LIMA, J. F.; WADI, Y. A população urbana e a difusão das cidades de porte médio no Brasil. Interações, Campo Grande, v. 14, n. 2, p. 251-265, jul./dez. 2013.

ZÜGE, R. M.; SOBRINHO, J. C. R.; CORTADA, C.; CABRAL, D. Manual de armazenamento e transporte de embalagens de agrotóxicos e produtos de uso veterinário. Curitiba: TECPAR, 2009. 